\title{
ISIZULU TEACHERS' PERCEPTIONS OF THE FOUNDATIONS FOR LEARNING LITERACY PROGRAMME IN FOUR TOWNSHIP PRIMARY SCHOOLS
}

Thabile Mbatha

University of KwaZulu-Natal

This article reports on a study that was conducted to investigate how isiZulu-speaking teachers teaching Grade $R$ to Grade 3 in four Pietermaritzburg township schools in KwaZulu-Natal have received the Foundations for Learning Programme (FLP), launched by the national Department of Education as a response to drastic deficiencies in reading and writing skills that have recently been confirmed among South African learners. In total, 14 Foundation Phase teachers participated in an interview-based study on their perceptions of the programme. Findings of the study indicate considerable uncertainty and unevenness in the way teachers interpret the FLP, and teachers of isiZulu in particular reported inability to engage with the programme because it was published in English and no isiZulu version was available. The conclusion is that the DoE must provide FLP resources in isiZulu so that teachers are enabled to use the programme for improving isiZulu literacy skills among learners.

\section{INTRODUCTION}

Two recent investigations, the Progress in International Reading Literacy Study (PIRLS, 2006) and the series of studies reported in 2005 by the SACMEQ II Project of the Southern African Consortium for Monitoring Educational Quality, draw attention to very serious problems with literacy development in South Africa. Corroborating these appraisals, the systemic evaluation reported by the South African Department of Education (DoE) in 2007 (DoE, 2007) gave an average Grade 3 achievement score for literacy of just 36\%. Fleisch (2008) warned that poor literacy skills constitute a 'crisis' in South African education (See also Kruizinga \& Nathanson, 2010). The Annual National Assessment (ANA) results published in June 2011 by the Department of Basic Education (DBE) show no improvement on the previous evaluations, with the Grade 3 national average performance in literacy being $35 \%$.

The Foundations for Learning Campaign, also referred to as the Foundations for Learning Programme (FLP), launched by the DoE in 2008 (DoE, 2008c:4-23), can be seen as a crisisresponse drive, at national level, to provide serious additional thrust in tackling these grave shortcomings in South African education. The FLP puts its focus on improving the reading, writing and numeracy abilities of all South African children, with accompanying directives for teachers and schools, setting out expectations for arriving at the targeted levels of performance. The Government Gazette (DoE, 2008c:4-23) announcement also advised that a culminating national evaluation of literacy and numeracy in Grades 3 and 6 would be conducted at the end of 2011 to assess the impact of the campaign. Against this background, 
the aim of the research on which this paper is based was to investigate how teachers themselves understand and give meaning to the FLP.

At the Foundation Phase conference held to introduce the FLP, keynote speaker Hallingsworth (2008) stated that 'The goal of literacy is to teach children to understand and communicate well in national languages.' She argued that 'it is faster to obtain literacy through the mastery of their national languages and it also preserves the ability to communicate with family and friends in traditional cultures.' In his address, Sampa (2008) added that initial language acquisition needs to be meaningful, especially at the foundation stage of learning, where it is imperative that both the learners and the teachers use a language that ensures a strong foundation for early literacy learning. In South Africa, many children are denied the right of being taught in their home language because they are introduced to literacy in English as early as in pre-school and early grades of schooling. This is fatal for their progress because literacy in the home language is a crucial requisite for gaining proficiency in an additional language.

\section{FOCUS, PURPOSE AND RATIONALE}

This paper is focused on teaching literacy in isiZulu as the home language. The purpose of the study was to consider how isiZulu home-language teachers understand the FLP, how they perceive the use of isiZulu as a language of learning and teaching (LoLT) in the Foundation Phase classrooms for introducing literacy, and how they build on the strengths of children's home languages to forge links which will be a foundation for future learning. The study springs from my own work as a Foundation Phase teacher educator, lecturing to Foundation Phase isiZulu literacy students on teaching. I wanted to understand why some teachers were reluctant to use the FLP in their classrooms and why my students were finding it difficult to practice the methods advocated in the FLP. Furthermore, I wanted to establish whether the impact of the FLP on literacy skills of Grades R-3 learners would be fairly assessed at the end of 2011, in the light of the teachers' perceptions of the FLP in teaching literacy in the Foundation Phase.

The declared goals of the FLP are to improve teaching literacy and numeracy in the Foundation Phase so as to address the challenges that were identified in the systemic evaluations already mentioned: PIRLS (2006), SACMEQ (2002-2003), and the South African DoE Systemic Evaluation (2007). If teachers embrace the goals of the FLP, this could mean that their teaching may indeed establish the fundamental literacy skills that are so crucial for learners' ultimate progress. This study worked on the assumption that if teachers use the appropriate methods, learners should master the basics of reading and writing at an early stage and also that teachers who understand the role of the learners' home language in learning will utilise its strengths so that learners transfer the literacy skills learnt in the home language into learning literacy in an additional language.

\section{RESEARCH QUESTIONS}

- What is the isiZulu teachers' understanding of the purpose and goals of the Foundations for Learning Literacy Programme?

- How do teachers perceive use of isiZulu as a language of learning and teaching in Foundation Phase classrooms as a means to achieve the goals of the Foundations for Learning Programme? 


\section{UNDERLYING DISCOURSES IN TEACHING EARLY LITERACY IN SOUTH AFRICA}

Kress (1989) defined discourses as 'systematically organised sets of statements which give expression to the meanings and values of an institution. They are institutionally defined, socially acceptable ways of thinking, saying or doing' (1989:7). Discourses also determine what is acceptable to say and what is not acceptable to say (and, by extension, what one may do or may not do) with respect to the area of concern, whether marginal or central, of that institution.

The discourses that guide the teaching of early literacy in South African schools are outlined in the National Curriculum Statement (NCS) (DoE, 2002), the DoE's Language in Education Policy document (1997) and the Foundations for Learning Programme (DoE, 2008a). The NCS stipulates that teaching in the Foundation Phase should be conducted in the home language of learners. The FLP outlines how beginning literacy should be taught in the South African context, including the methodology for teaching literacy and the successive milestones that learners should reach in the home languages and in additional languages. The Language in Education Policy (LiEP), on the other hand, promotes multilingualism (or additive bilingualism) in conjunction with mother-tongue teaching. Discourses that have particular relevance for this study are as follow:

- the national curriculum for and language policy on education in South Africa

- the role of literacy in the home languages

- a balanced approach to literacy and guided reading and writing.

In each case, these are discourses which the Foundations for Learning Programme implicitly assumes to be established underpinnings of recommended classroom practice in South African schools.

\section{THE NATIONAL CURRICULUM AND LANGUAGE POLICY IN EDUCATION}

The discourse of multilingualism enshrined in the South African Constitution (1996) has shaped approaches to teaching literacy in schools by promoting biliteracy and indicating the need for all learners to be literate in their home languages and in additional languages. In South Africa, classes typically include learners from diverse backgrounds, and multilingualism is a characteristic of learners' linguistic repertoires. Heugh (2002) and Van der Walt (2009) noted that although the 1997 South African Language in Education Policy fully promotes multilingualism, the type of multilingualism it refers to differs from the type described in sociolinguistic studies and is best understood as code-switching. Van der Walt (2009:32) argued that the policies of language use are not clearly articulated in either LiEP or in the NCS. She pointed out that the policy context in South Africa supports 'an additive approach to bilingualism as the normal orientation'. Schools have to develop LiEPs with their school governing bodies (SGBs) and 'must stipulate how the school will promote multilingualism through using more than one LoLT or by offering additional languages as fully fleshed subjects and/or applying special immersion or special language maintenance programmes or through other means approved by the head of the provincial education department' (Van der Walt, 2009:32). 
Van der Walt noted further that although the NCS stipulates that the mother tongue should be used a language of learning and teaching in the Foundation Phase, the strategy for doing this is left to individual schools and provincial education departments. Teachers are given a generic curriculum statement on the use of home languages and additional languages which is often unclear about the principle of multilingualism. This means that teachers of different home languages all have to follow the same NCS teaching guidelines for their respective languages. For example, isiZulu home language teachers are expected to use similar teaching methods to those that apply to English home language, the only difference being the content of the lessons. This is distinctly problematic because the differing language scenarios may not allow translation of teaching principles from one language to another.

\section{LITERACY IN A HOME LANGUAGE}

Cummins $(1982,1996,2000,2005)$ and Heugh (2002) argued that using the home language as a resource for reading is advantageous because children who learn reading skills in their home language are able to transfer the skills in learning to read to another language. Drawing on developmental interdependence theory, Cummins (1996:55) argued that high levels of proficiency in the home language enable similar levels to be attained in the second language. In contrast, when skills in the home language are not well developed, and education in the early years is exclusively in the second language, further development in the home language will be stunted. The 'dual iceberg' theory also proposed by Cummins (1982 argued that there is a common underlying proficiency (CUP) which means that the thoughts that accompany talking, reading, writing and listening come from the same central engine, irrespective of the language in which a person is operating (Baker, 1996:147). Skutnabb-Kangas (2000) and Ball (2010) maintained that many of the skills acquired in the first language can be transferred to the second language. Developing the home language is easier and thus can lay a solid foundation for learning the second language. Besides these benefits, the home language also brings its speakers together because it is the language that embodies their culture.

\section{BALANCED APPROACH TO LITERACY WITH GUIDED READING AND WRITING}

Taking their cue from what has come to be known as New Literacy Studies (NLS), and steering clear of either bottom-up or top-down approaches, the DoE (2002) and Joubert, Bester and Meyer (2008) recommended a balanced approach to the development of literacy in which reading and writing skills are taught and practiced simultaneously. Such an approach, Joubert et al. (2008:94) argued, is not so much a reading method as an orientation in reading and general literacy teaching, tailored to specific learners' needs and progress. Home language becomes particularly relevant in this approach.

\section{Guided Reading and Guided Writing}

Guided reading is a strategy to improve reading comprehension, in which a teacher in the literacy classroom supports each reader's development of effective strategies for processing texts at increasingly challenging levels of difficulty (Fountas \& Pinnell, 1996:2). It puts the focus on construction of meaning, with problem-solving strategies for learners to figure out words they do not know, deal with tricky sentence structure, and understand concepts and ideas they have not previously met in print. READ (2009) and Kruizinga and Nathanson (2010:68) described guided reading as a teaching method where children are taught how to 
construct meaning independently from a text, under a teacher's supportive guidance, and is particularly appropriate for children in the early years of literacy development and for the lowest performing learners. The teacher works with a small group of children who are able to read similar levels of texts with support (Hornsby, cited in Kruizinga \& Nathanson, 2010:68). Vygotsky's social constructivist theory and the concept of a balanced instructional approach (see also DoE, 2008b) are theoretical underpinnings of the method, and in teaching children how to construct meaning of a text through cognitive and social processes, guided reading falls in line with the underlying premises of the FLP.

Guided writing involves small group activities in which learners are led to apply and practice good writing skills (Wren, 2003). Children engage in writing a variety of texts (Fountas and Pinnell, 1996:23), and the teacher guides the process and provides instruction through mini lessons and conferences. At Grade 2 or Grade 3 level, learners might prepare to write a letter to someone that relates to what they discussed in a core content section. The teacher explains how it should be written and the learners then write a rough draft of their letters. Each learner proofreads his/her own letter, completes a checklist for guided writing, and then asks a friend to read a rough draft. In the next stage of the activity, the teacher asks each learner to read his/her own work and also shows learners how to give feedback.

\section{RESEARCH METHODOLOGY}

In conducting the presented study, I, the researcher, investigated how Foundation Phase teachers regarded their experiences of teaching the FLP in four township schools. Babbie and Mouton (2004) claimed that exploratory studies are suitable for researchers who desire to gain better understanding of phenomena. In the case of the FLP, discovering how teachers use the programme, relative to its intended purpose, will be helpful for assessing its impact and allowing ambiguities to be clarified in a timely manner As the primary objective in an exploratory study is to gain insight into the problem situation, in-depth interviews can be a useful way to elicit detailed information about personal feelings, perceptions and opinions discovering how individuals think and feel about a topic and why they hold certain opinions. During the research study, qualitative interviews were conducted with 14 teachers to gather their impressions.

\section{SELECTION OF PARTICIPANTS}

The sample was purposively selected to include heads of the Foundation Phase (FP) departments in the schools and educators who were mentors of student teachers (on placement in the schools for teaching practice as part of their Postgraduate Certificate in Education programme at a university in KwaZulu-Natal). I met the mentor teachers and - following due ethical procedures and with permission obtained from the school principals - requested them to participate in interviews about their understanding and teaching of the Foundations for Learning Programme. Teachers who gave written consent were assured that their participation was voluntary and did not form part of any performance appraisal. Teachers' names and the names of their schools were protected in the study by using codes in conformity with the university's ethical requirements. Data were collected by the researcher by interviewing teachers individually at various times during the April-to-May and the July-to-August teaching practice periods in 2010. Interview schedules were provided for the teachers to consider ahead of the interview, and an oral interview with the researcher then followed. Some teachers completed the semi-structured interview schedule in writing, in which case, the 
subsequent interview probed various points in their responses. The teachers' responses were coded in a table which listed each of the questions and later pruned out repetition of points.

\section{DATA COLLECTION}

Interviews were based on the following set of open-ended questions:

- What is your understanding of the purpose of the introduction of the Foundations for Learning Programme in primary schools in 2008 ?

- How do the guidelines provided in the FLP for teaching literacy help you in teaching literacy in the Foundation Phase?

- In your opinion, how does the FLP improve teaching and learning literacy in the FP?

- $\quad$ Please explain your response to the above question.

- What is the language of teaching and learning you use in your classroom?

- $\quad$ Please explain why you use it.

- If you are using isiZulu as a language of learning and teaching in your classrooms in achieving the goals of the Foundations for Learning Programme, how do you use it?

- How does using isiZulu as a language of learning and teaching affect teaching FP?

\section{DATA ANALYSIS AND INTERPRETATION}

Teachers were the units of analysis in the study. Their responses to the interview questions were analysed qualitatively in relation to categories identified from the interview questions, the overall purpose of the FLP, and strategies for implementing it in FP classrooms. The analysis attempted to look at what teachers find to be of value in the FLP. The responses were analysed and considered in relation to the literature on current discourses of multilingualism and multilingual education, the role of the home language in teaching early literacy in South Africa, and methods of teaching literacy advocated in policy documents.

\section{GENERAL PERCEPTIONS OF THE FLP}

Responses to the question of how teachers understood the FLP were grouped into positive and negative perceptions.

\section{Positive perceptions:}

- It is good for teaching literacy.

- It is easy to work with.

- It promotes using the mother tongue or home language (MT/HL).

- It is good, depending on teachers' mind sets.

- It says learners should be taught in their HL.

- It is good for literacy.

- It's easy to work with and places emphasis on literacy and numeracy.

\section{Negative perceptions:}

- $\quad$ The language is confusing with teaching numeracy.

- $\quad$ There's confusion in numeracy.

- It's new to teachers.

- $\quad$ There's too much work. 
- It does not state themes and shows no integrations of learning programmes.

- $\quad$ Teachers are struggling to teach the FLP as it is new to them.

- It doesn't work because it says every learner should pass.

- It still needs to be clearly introduced to educators.

- It is a good programme but teachers are overloaded with work.

- $\quad$ Teaching methods and assessment methods are not explained.

- I haven't spent quality time.

- Education changes now and then.

- $\quad$ Changes occur too often without training.

Although the FLP was accepted positively by the teachers, their understanding of the programme indicated a considerable degree of confusion and misunderstanding. Respondents described the programme as good and easy to work with, but none of them made any mention of the FLP's declared primary objective, namely to 'improve the reading, writing and numeracy abilities of all South African children' (DoE, 2008a:4). Although it was a declared intention of the FLP that the programme would 'provide teachers and schools with clear directives on the Department of Education's expectations of schools and teachers to achieve the expected levels of performance', the general uncertainties about the programme that respondents tended to display gave little confirmation that such directives had succeeded in their purpose.

A further lack of understanding revealed in some teachers' responses was that they mistakenly thought the FLP was a curriculum change; there were comments that education policies seemed to change too often with no adequate training for the new intervention. In fact, the South African curriculum has not changed since its last revision in 2005, and the FLP and the National Reading Strategy are additional support initiatives intended to supplement the existing curriculum, not change it.

Teachers also commented that some details were missing from the FLP, although the details that were said to be missing are actually contained in other documents to be used in conjunction with the FLP. The misunderstanding here is that the FLP does not replace existing Foundation Phase documents, and NCS assessment strategies remain unchanged; rather, the FLP clarifies the milestones that learners must reach during the four terms in each grade. This kind of misunderstanding would explain the implicit dismissal of the FLP by teachers who complained that it was confusing.

One respondent seemed to think that FLP was meant to change her way of teaching, complaining that, unlike the NCS, it failed to emphasise theme teaching. Here too, the complaint reflected a failure to understand that the FLP in no way displaced the NCS, but was intended instead to give integrated reinforcement to the existing literacy curriculum. It was not clear to the teachers that the FLP should be read in conjunction with the NCS and existing supplementary documents and that the NCS remains unchanged. 


\section{PERCEPTIONS OF FLP GUIDELINES FOR TEACHING LITERACY}

A degree of ambiguity was encountered in responses on the FLP guidelines for teaching literacy, and a surprising feature was that the only problems mentioned in comments on the guidelines were to do with numeracy teaching.

Positive perceptions:

- Good in oral skills and builds language skills.

- Good for teaching vocabulary.

- $\quad$ Clear weekly guidelines are provided for literacy and they tell teachers where to start and end.

- It tells the teachers where to start and where to end.

- It is good for teachers with more than 10 years of experience.

- $\quad$ Enough reading time is given in literacy.

- $\quad$ Learners are given a lot of reading time which helps in learning to write.

- It is flexible and allows learners to be free to talk.

Negative perceptions:

- $\quad$ Numerals are easier in English; isiZulu translations are too long.

- $\quad$ Numeracy lesson plans are too detailed but good for learners who have not attended pre-school.

The majority of respondents indicated approval of the general FLP guidelines for Foundation Phase literacy teaching. The FLP lists six learning outcomes - speaking, listening, reading, writing, thinking and reasoning, and language use - and teachers' comments suggest endorsement of the FLP because the guidelines give attention to this full range of literacy practices.

Positive features that respondents cited in relation to the guidelines included the increased time allocation for teaching reading, the prioritising of reading and writing (where the need was greatest), and the setting out of syllabus and content per grade, with milestones that specify the content that should be covered in each term. The teachers approved of the FLP for telling them clearly where to start and where to end, helping them to plan their teaching based on the content and syllabus.

Respondents mentioned that the FLR guidelines for Foundation Phase teaching of phonics listed the sounds to be covered, but not the methodology; there was, for instance, an explicit list of the phonics in English that were to be covered in Grades 1 and 2. One teacher expressed reservations about the phonics approach, commenting that children can spend a long time learning sounds and still not become readers.

\section{FAMILIARITY WITH TEACHING METHODS MENTIONED IN THE FLP}

Comments from teachers on their familiarity with the teaching methods and the strategies for teaching literacy that are envisaged in the FLP included the following:

- It uses the conventional methods of teaching.

- $\quad$ There's a problem with teaching writing. 
- It gives guidelines and direction of lessons.

- $\quad$ Group work is used.

- $\quad$ Phonic method is difficult because a child takes long doing the single consonants.

- $\quad$ Teachers need to put effort to implement it and also need parental involvement.

- Government must ensure that adequate resources and workshops are conducted.

- We enjoy the teaching strategies but there was a lot of reading that needed to be done before we teach particular lessons.

- $\quad$ The FLP is something new. There was no training of teachers in the strategies used. These strategies make teachers to be strangers in their own classes.

- $\quad$ Some are familiar, some are not.

- $\quad$ [The FLP] tells us to group learners but the tasks are not for groups but for the whole class.

Seven teachers said that the teaching methods were familiar but they felt pressurised by the programme because of the national annual assessments. They also commented that the sequence and pacing of lessons presented difficulties for them. While the FLP teaching methods and strategies were in general said to be familiar, teachers nonetheless indicated uncertainty about the more specific significance of these approaches as recommended by the programme. They also indicated that while various guidelines were provided on the teaching of literacy, the aspect of writing remained problematic. The level of uncertainty about the overall import of the FLP and the teaching methods which it advocates is suggested in the comments from some of the teachers that they needed to be trained because the FLP was a new programme, even though the FLP was already in its 3rd year and due to be evaluated in its 4th year. This kind of gap in understanding seems to underlie the mixed responses from the teachers, with some giving the programme partial approval and others saying they are confused by it.

Among the criticisms levelled against the FLP was that it specified content but failed to give sufficiently explicit guidance on teaching methods, a case in point being the criticism that group teaching was recommended but the only tasks suggested by the programme were for whole-class teaching and thus unsuitable for teaching in smaller groups. Another such criticism was lack of emphasis on the teaching of writing. One teacher objected to exclusive use of phonics, although this is not in fact what the FLP advocates; rather, it promotes the balanced approach widely advocated in current discussions - as in Joubert et al. (2008) and the Teachers' Handbook for Teaching Reading in the Early Grades (DoE, 2008b). It was notable that, apart from the misplaced criticism of phonics, teachers' responses tended not to engage specifically with methods currently used in teaching literacy studies in the early grades. This relative silence would seem to indicate wider uncertainty about teaching methods that would limit the benefit teachers could derive from the FLP.

Part of the design of the FLP was to provide necessary support to teachers for achievement of the campaign objectives. Respondents complained that this support had not been forthcoming, but their criticism suggested a failure to grasp that the FLP had never been conceived as an exclusive method but rather as supplementing or reinforcing existing guidelines already contained in documents such as the Teacher's Handbook on Teaching Literacy in the Early Grades (DoE, 2008b) and the National Reading Strategy. 


\section{LoLT AND RESOURCES FOR TEACHING ISIZULU LITERACY IN THE FLP}

The teachers had much to say about LoLT and the availability of isiZulu teaching resources, as indicated in several of the responses listed below:

- $\quad$ Reading is done daily -- it will raise the standard of reading that is lacking.

- It can be fruitful as long as the Department can supply teachers with teaching aids.

- $\quad$ Literacy programme is good. Learners are free to interact in their mother tongue (MT).

- Learners learn new things but [some] are more advantaged than others by learning things that are familiar.

- $\quad$ Resources are limited to children not exposed to modern life e.g. television where learners look at TV programmes before learning from the teacher.

- $\quad$ Teachers should be supported with teaching aids and teacher-learner ratios reduced to 1:35.

- $\quad$ The oral in the MT is good but more resources should be provided in the MT.

- It depends on the LoLT that the school is supporting.

- It depends on the LoLT in the school - isiZulu literacy is taught well using the old methods.

- It's difficult in teaching phonics in isiZulu. Not the same as in English.

- It's tough to change to isiZulu.

- We are slowly getting there though it is difficult to teach in isiZulu.

- $\quad$ There is no isiZulu FLP.

A recurring issue was methods of teaching literacy in isiZulu. Several teachers indicated that this was a problem for them, although one said that colleagues were mostly familiar with teaching literacy in isiZulu but it simply was not taught well enough.

Apart from one teacher who had a positive view about using isiZulu as the LoLT, teaching literacy through the medium of isiZulu was the teachers' biggest problem, because suitable teaching resources were not available in that language. Another possible source of difficulty was the language policy of individual schools, with several teachers making the point that it determined the LoLT used in that school. The LoLT was often mentioned in conjunction with shortage of isiZulu learning materials.

All the teachers indicated that the availability of isiZulu resources in the schools is very limited and that the Education Department needs to rectify this deficiency. They made the criticism that the FLP was designed for English as the home language and not isiZulu, leaving teachers to rely on their own ability to translate the requirements of the programme from English to isiZulu. In the absence of a standardised vocabulary and methods of teaching isiZulu literacy, teachers are, in practice, left on their own, with no adequate teaching resources, creating a huge challenge for using isiZulu as a LoLT.

Although the NCS and the LiEP stipulate that the 'learner's home language should be used for learning and teaching whenever possible' and that this 'is particularly important where children learn to read and write' (DoE 1997, 2002) the teachers complained that the FLP fails to cater for home languages, such as isiZulu, as the LoLT. Of the 14 respondents, 10 were not 
in of favour of using a home language as the LoLT and instead advocated the introduction of English in Grade 1. They argued that the education system does not cater for the home language as a LoLT beyond the Foundation Phase, out of concern that children will suffer because of inadequate grounding in English. Only four teachers took the view that using isiZulu as the LoLT boosts the learner's morale and builds self-confidence and self-esteem. Most of the isiZulu home-language teachers saw no relevance to their teaching in the FLP, and they identified several obstacles to using isiZulu as the LoLT within the programme. They argued that isiZulu does not prepare learners for English, which is the medium of instruction for all learning areas in the Intermediate Phase (Grade 4-6) and upwards in the education system. They added that teaching in isiZulu is very slow and difficult, especially teaching numeracy in isiZulu.

Failure to provide FLP guidelines in isiZulu was criticised by one respondent on the grounds that for isiZulu teachers to adapt the English version on their own was too time consuming and not practicable because English and isiZulu have totally different language systems. Conceived for teaching in English, the FLP, she felt, was just not appropriate for isiZulu. Another respondent argued that while the challenges of using isiZulu as the LoLT could be minimised if isiZulu was the LoLT throughout their schooling, learners do need to switch to English as the LoLT, making it less surprising that isiZulu was not catered for by the FLP. Some teachers questioned the principle of using the home language in relation to the FLP. They regarded the FLP as having been tailored specifically for English as home language and felt that translating its recommendations would have little benefit for isiZulu as a home language. Notwithstanding the case made by scholars such as Cummins (1982, 1996, 2000), Heugh (2002), and Baker (1996) for using the home language as a resource for reading, these respondents were not inclined to engage much with isiZulu in the Foundation Phase because they wanted to move on to teaching English. Although learners were taught how to read in isiZulu, it would seem that the teachers did not see it as a resource that would facilitate reading in an additional language. Links between the two languages were not an issue that drew forth much discussion from the respondents.

\section{OVERALL PERCEPTIONS OF THE FLP BY THE TEACHERS}

1. Some respondents seemed to confuse the FLP with a change of the curriculum, replacing the NCS, which is not the case. The FLP is simply a supplement to the NCS to boost learner performance in reading and writing. The responses suggest that although workshops are conducted, some teachers seek on-going support without fully understanding the objectives of the campaign.

2. Respondents commended the FLP guidelines for telling them clearly where to start and where to end. However, at the same time, they complained that they were given insufficient guidance on the literacy teaching approaches they were required to follow, such as methodology for teaching writing. There was no acknowledgement by any of the respondents of established teaching strategies such as guided reading, shared reading or the balanced approach to teaching literacy; guidelines on teaching methods were simply said to be missing is in the FLP document. This criticism indicated a failure to recognise that the FLP is supplementary to the teaching guidelines already provided in the DoE's (2008b) Teaching Reading in the Early Grades: A Teacher's Handbook. 
3. Respondents saw the issue of home language use in literacy teaching as inseparably linked to the lack of teaching resources in isiZulu. They pointed out that the LiEP and the NCS stress the importance of using the learners' home language as the LoLT, yet none of the guidelines provided in the FLP were available in isiZulu. It is indeed hard to escape the conclusion that home language plays second fiddle to English in the way the FLP was envisaged. Lack of teaching resources in isiZulu is a serious obstacle for the teaching of Literacy in isiZulu as a home language. The wider picture that emerged from the teachers' responses is that English is the language in demand and because parents cannot afford to send their children to well-resourced schools in town, this puts pressure on isiZulu language teachers to teach literacy in English, even though resources in English are also in short supply in their schools.

4. There was a lack of clarity about the purpose of the FLP. One respondent suggested that the campaign was working well but quickly added that teachers needed to put more effort into implementing it and that it also needed parental involvement. Analysis of the interview responses suggested that this kind of effort on the part of the teachers was often not forthcoming and that their lack of engagement with the FLP went hand in hand with inadequate understanding of its purpose.

\section{CONCLUSION}

The study set out to determine how isiZulu home language teachers understand the Foundations for Learning Programme and how the FLP influenced their use of isiZulu as a LoLT for teaching literacy skills in Foundation Phase classrooms that would be subsequently transferrable for future learning in an additional language.

The findings of the study suggest that teachers were uncertain about the purpose and goals of the FLP. The teachers' understanding was generally not congruent with the goals of the FLP and several teachers could not indicate any positive assistance they had gained from the FLP for teaching literacy. The problem for FLP implementation which teachers most frequently mentioned was the difficulty of using isiZulu as a LoLT without appropriate teaching resources in isiZulu, and they linked this to the failure of the FLP to provide any of its material in isiZulu.

Lack of teacher training is clearly a problem for the FLP campaign. In general, the teachers took the view that the FLP was the government's programme and that the government must provide resources and teacher workshops for it to be implemented in the schools. Teachers acknowledged that the FLP had some positive factors in its guidelines for improving the teaching of literacy, but they were unable to say how the FLP improved their own teaching.

\section{REFERENCES}

BABBIE, E. \& J MOUTON. 2004. The Practice of Social Research. OUP, Cape Town.

BAKER, C. 1996. Foundations of Bilingual Education and Bilingualism. Clevedon, UK: Multilingual Matters.

BALL, J. 2010. Enhancing learning of children from diverse language backgrounds: Mother tonguebased bilingual or multilingual education in the early years. Geneva, Switzerland: UNESCO. 
CUMMINS, J. 1982. Bilingualism and minority language children. Toronto, ON: OISE.

CUMMINS, J. 1996. Negotiating identities: Education for empowerment. Covina, CA: California Association for Bilingual Education.

CUMMINS, J. 2000. Language power and pedagogy: Bilingual children in the crossfire. Clevedon, UK: Multilingual Matters.

CUMMINS, J. 2005. Teaching for cross language transfer in dual language transfer in dual medium language education: Possibilities and pitfalls. Paper presented at the TESOL Symposium on Dual Language Education. Istanbul, Turkey, 23 September 2005.

DEPARTMENT OF BASIC EDUCATION. 2011. Statement by the Minister of Basic Education, Mrs Angie Motshekga on the release of the ANA results for 2011. 28 June 2011. Pretoria.

Accessed on 08/07/2011. Available at http://www.education.gov.za/Newsroom/Speeches/tabid/298/ctl/Details/mid/1390/Item1 .

DEPARTMENT OF EDUCATION, 1997. Language in Education Policy.Pretoria, RSA:. Accessed 10/06/2011. Available at http://www.education.gov.za/Documents/policies/Language EducationPolicy1997.pdf .

DEPARTMENT OF EDUCATION, 2002. Isitatimende esibukeziwe sohlelo lwezifundo sikazwelonke samabanga R-9 (Ezikoleni): Incazelojikelele, Pretoria, RSA: Government Printers.

DEPARTMENT OF EDUCATION. 2003. Report to the minister: Review of the financing, resourcing and costs of education in public schools. March 3. Pretoria: Department of Education.

DEPARTMENT OF EDUCATION. 2007. Systemic evaluation foundation phase. Leaflet [online]. Accessed 10/06/2011. Available at http://www.education.gov.za/dynamic/dynamic.aspx/pageid=326\&dirid=56

DEPARTMENT OF EDUCATION. 2008a. Foundations for learning assessment framework. Foundation Phase. Pretoria, RSA: Government Printers.

DEPARTMENT OF EDUCATION. 2008b. Teaching reading in the early grades: A teacher's handbook. Pretoria, RSA: Government Printers.

DEPARTMENT OF EDUCATION. 2008c. Government Gazette No. 30880. Pretoria, RSA: Government Printers.

FLEISCH, B. 2008. Primary education in crisis: Why South African school children underachieve in reading and mathematics. Cape Town, RSA: Juta.

FOUNTAS, I.C. \& PINNELL G. S. 1996. Guided reading: Good first teaching for all children. Portsmouth, UK: Heinemann.

GEE, JP. 1990. Social linguistics and literacies: Ideology in discourses, critical perspectivesm on literacy and education. London, UK: Falmer Press.

GOVERNMENT OF SOUTH AFRICA. 1996. South African Constitution.

KRESS, G. 1989. Linguistic processes in sociocultural practice. Oxford, UK: Oxford University Press.

HALLINGSWORTH, S. 2008. Developing instructional approaches based on early grade reading assessment: Lessons from Mali and Niger. Paper delivered at the Foundation Phase conference held at Mokopane, Limpopo 30 September - 1 October.

HEUGH, K. 2002. The case against bilingual and multilingual education in South Africa: Laying bare the myths. Perspectives in Education 20(1):171-196.

JOUBERT, I., M BESTER \& E MEYER. 2008. Literacy in the foundation phase. Pretoria, RSA: Van Schaik. 
KRUIZINGA, A \& R NATHANSON. 2010. An evaluation of guided reading in three primary schools in the Western Cape. Per Linguam 26(2):67-76.

McGUINNESS, D. 2005. Language development: The scientific study of how language development affects reading. Cambridge, MA: MIT Press

MTSHALI, N. S. SMILLIE \& SAPA Many SA kids can't read or write. The Star: 29 June 2011. http://www.iol.co.za/news/many-sa-kids-can-t-read-or-write-1.1090583

NEETHLING, B. 2010. Xhosa as medium of instruction in higher education classrooms: A Pie in the Sky? Per Linguam 26(1): 61-73.

PROGRESS IN INTERNATIONAL LITERACY STUDY. 2006. PIRLS 2006 International Report. Boston, MA: TIMMS \& PIRLS International Study Centre:.

SAMPA, F. 2008. Keynote address delivered at the Foundation Phase conference held at Mokopane, Limpopo, 30 September

SCARBOROUGH, HS. (2001). Connecting early language and literacy to later reading (dis)abilities: Evidence, theory, and practice. In Neuman, S \& D Dickinson (Eds.), Handbook for research in early literacy. New York, UK: Guilford Press. 97-110.

SKUTNABB-KANGAS, T. 1984. Bilingualism or Not: The Education of Minorities. Clevedon: Multilingual Matters.

SKUTNABB-KANGAS, T. (ed). 1995. Multilingualism for all. Lisse, Netherlands: Swets Zeitlinger.

SKUTNABB-KANGAS, T.: 2000, Linguistic genocide in education - or worldwide diversity and human rights?, Mahwah, NJ, Lawrence Erlbaum.

STREET, B. 1984. Literacy in theory and practice. Cambridge, UK: Cambridge University Press.

STREET, B. 1996. Preface. In Prinsloo, M \& M Breier Eds). The social uses of literacy. Amsterdam, The Netherlands: John Benjamins.

STREET 2003. What's 'new' in New Literacy Studies? Critical Approaches to Literacy in Theory and Practice. Current Issues in Comparative Education 5, 2.

VAN DER WALT, C. 2009. The functions of code-switching in English language learning casses. Per Linguam, 25 (1):30-43.

WREN, S. 2003. What does a balanced approach to reading instruction mean? Accessed 10/06/2011 from http:www.balancedreading.com/balancedhtml

\section{BIOGRAPHICAL NOTE}

Thabile Mbatha is a lecturer in the School of Education and Development at the University of Kwazulu-Natal. Her interests are in Foundation Phase mother tongue literacy, teaching reading, English additional language pedagogy, IsiZulu home, first and second additional language teaching and barriers to learning (language barriers as well as HIV/AIDS).

Email address: mbathath@ukzn.ac.za 